\title{
ANALISIS BIAYA DAN PENERIMAAN USAHATANI TOMAT DI DESA WAKULI KECAMATAN KAPONTORI KABUPATEN BUTON
}

\author{
Suriadi \\ Program Studi Agribisnis Fakultas Pertanian \\ Universitas Muhammadiyah Buton \\ Jln. Betoambari No. 36 Baubau \\ e-mail: Suriadivah@yahoo.com
}

\begin{abstract}
Problem statements in this research are: how much is the cost incurred by farmers in tomato farming in Waklii Village, Kapontori Sub-district, Buton Regency and how much is the income obtained from tomato farming in Wakuli Village, Kapontori Sub-district, Buton Regency. This study aims to determine how much the average cost received by farmers from tomato farming in Wakuli Village, Kapontori Sub-district Buton Regency and how much the average income received by tomato farmers in Wakuli Village, Kapontori sub-district, Buton Regency, this research was carried out in Wakuli Village, Kapontori Sub-disctrict of Buton Regency for two months from June to July 2015. The population of this study was existing tomato farmers, the research sample took 30 tomato farmers. Data were collected through interviews using questionnaires and data analysis using cost and revenue analysis. The results showed that the costs incurred by farmers in conducting tomato farming activities with an average land area of 1 ha with an average cost of IDR. 5,715,983 and the average acceptance of IDR 14,303,667, with the average income of the respondent farmers, is IDR 8,587,983. Recommendations Local governments, especially at the regency level, need to establish regulations relating to the tomato marketing system, especially determining basic prices.
\end{abstract}

Keywords: cost and acceptance analysis, tomato farming

\begin{abstract}
Abstrak
Rumusan masalah penelitian adalah: Berapa biaya yang dikeluarkan petani pada usahatani tomat di Desa Wakuli Kecamatan Kapontori Kabupaten Buton dan Berapa Penerimaan yang diperoleh dari usahatani tomat di Desa Wakuli Kecamatan Kapontori Kabupaten Buton. Penelitian ini bertujuan untuk mengetahui berapa besar rata-rata biaya yang diterima oleh petani dari usahatani tomat didesa Wakuli Kecamatan Kapontori Kabupaten Buton dan Berapa besar rata-rata penerimaan yang diterima petani tomat di desa Wakuli Kecamatan Kapontori Kabupaten Buton. Penelitian ini di laksanakan di desa Wakuli Kecamatan Kapontori Kabupaten Buton selama dua bulan dari bulan Juni sampai bulan Juli 2015. Populasi dari penelitian ini adalah petani tomat yang ada, sampel penelitian mengambil petani tomat berjumlah 30 orang. Data dikumpulkan melalui wawancara dengan menggunakan daftar pertanyaan (quesioner) dan analisis data menggunakan analisis biaya dan penerimaan. Hasil penelitian menunjukan bahwa biaya yang dikeluarkan petani dalam rnelakukan kegiatan usahatani tomat dengan luas lahan rata-rata 1 ha dengan rata-rata biaya Rp. 5.715.983,- dan rata-rata penerirnaan Rp. 14.303.667,- dengan pendapatan rata-rata petani responden adalah Rp. 8.587.983,-. Rekomendasi pemerintah daerah terutama ditingkat kabupaten perlu menetapkan peraturan-peraturan yang berhubungan dengan sistem pemasaran tomat teratama penetapan harga dasar.
\end{abstract}

Kata Kunci: analisis biaya dan penerirnaan, usahatani tomat 


\section{PENDAHULUAN}

Sektor hortikultura yang meliputi komoditas sayuran, buah, tanaman hias dan biofarmaka merupakan salah satu sumber perolehan devisa yang cukup penting. Misalnya selama tahun 2001-2002 nilai ekspor sayuran dan buah menyumbang sekitar 12-17 persen nilai ekspor bahan pangan yang dihasilkan oleh sektor pertanian dan sektor perikanan (Irawan, 2003). Namun akhir-akhir Ini kinerja perdagangan hortikultura tersebut cenderung memburuk ditunjukkan oleh semakin banyaknya irnpor buah dan sayuran. Selama tahun tersebut neraca perdagangan hortikultura juga mengalami defisit dengan nilai defisit yang semakin besar akibat peningkaian nilai impor yang lebih tinggi dibanding nilai ekspor.

Pendapat yang mengungkapkan bahwa masalah pengembangan agribisnis hortikultura pada umumnya lebih terletak pada aspek di luar usahatani (off-farm) daripada aspek usahatani (on-farm) karena kendala pengembangan agribisnis hortikultura lebih banyak dijumpai pada aspek penanganan pasca panen dan pemasaran (Irawan, 2003). Oleh karena itu kebijakan pembangunan hortikultura yang hanya difokuskan pada aspek produksi atau usahatani belum mampu mendorong pertumbuhaa agribisnis hortikultura secara berkelanjutan selama permasalahan off-farm belum dapat diatasi. Pengalaman pada masa puncak krisis ekonomi telah membuktikan hal tersebut dimana penyaluran kredit usahatani kepada petani sayuran sebesar Rp. 800 milyar pada tahun 2011 tidak mampu mendorong peningkatan produksi sayuran secara berkelanjutan akibat instabilitas harga sayuran. Akibat penyaluran kredit tersebut produksi sayuran pada tahun 2011 memang naik sebesar 3,2 persen tetapi pada tahun 2000 turun sebesar 6,6 persen karena anjloknya harga sayuran.

Provinsi Sulawesi Tenggara merupakan salah satu penghasil tomat, dimana dari tahun ketahun mengalami peningkatan produksi yang cukup menggembirakan. Keadaan ini selain disebabkan meningkatnya luas panen juga karena semakin intensnya pemeliharaan yang dilakukaa oleh petani.

Desa Wakuli merupakan salah satu desa yang berada di Kecamatan Kapontori yang memiliki cakupan lahan sawah dan lahan kering yang memungkinkan lahan hortikultura. Desa Wakuli memiliki potensi lahan pertanian yang tinggi khususnya untuk pengembangan tanaman hortikultura. Komoditas yang dibudidayakan oleh petani di Desa Wakuli adalah tomat, cabe, kol, timun dan terong. Budidava tomat di Desa Wakuli mempunyai prospek balk untuk dikembangkan, karena permintaan konsumen terhadap tomat cukup besar dari pada komoditas yang lainnya.

Tomat adaiah tanaman yang paling mudah dijumpai. Warnanya yang cerah sungguh menarik. Selain kaya vitamin C dan A, tomat konon dapat mengobati bermacam penyakit. Namun yang menjadi kendala adalah harga tomat di pasaran nampaknya berfluktuasi, yang berarti harga tomat dari waktu ke waktu tidak stabil kadang-kadang rendah kadang- kadang tinggi yang dipengaruhi oleh berbagai keadaan seperti jumlah produksi dan permintaan. Untuk melihat luas tanam dan produksi tomat untuk Kabupaten Buton dan di Desa Wakuli Kecamatan Kapontori dapat dilihat pada Tabel 1 dan 2 berikut ini:

Tabel 1. Luas Lahan Panen Dan Produksi Tomat Di Kabupaten Buton Dari Tahun 2010-2012

\begin{tabular}{cccc}
\hline Tahun & Luas Tanam $(\mathrm{Ha})$ & Luas Panen $(\mathrm{Ha})$ & Persentase $(\%)$ \\
\hline 2010 & 185 & 165 & 4,562 \\
\hline 2011 & 141 & 137 & 7,140 \\
\hline 2012 & 164 & 163 & 8,551 \\
\hline
\end{tabular}

Sumber Data: Dinas Pertanian Kabupaten Buton, 2012.

Tabel 2. Luas Lahan, Luas Panen dan Produksi Tomat di Desa Wakuli Kecamatan Kapontori Kabupaten Buton dari Tahun 2010-2012 


\section{P-ISSN: 2527-8479}

\begin{tabular}{cccc}
\hline Tahun & Luas Tanam $(\mathrm{Ha})$ & Luas Panen $(\mathrm{Ha})$ & Persentase $(\%)$ \\
\hline 2010 & 67 & 67 & 1,122 \\
\hline 2011 & 38 & 33 & 1,785 \\
\hline 2012 & 10 & 8 & 44 \\
\hline
\end{tabular}

Sumber Data: Dinas Pertanian Kabupaten Buton, 2012.

Berdasarkan Tabel 2 di atas menunjukkan bahwa produksi tomat baik Kabupaten maupun Kecamatan Kapontori dari tahun 2011-2012 mengalami penurunan yang cukup signifikan. Hal ini disebabkan oleh beberapa faktor antara lain perubahan iklim, dimana curah hujan yang tinggi, serangan hama yang meningkat serta perlakuan yang tidak teratur. Hal lain adalah harga tomat tinggi ada kecendenmgan petani untuk menambah luas lahan yang diusahakan, intensitas pemilihan bibit dan penggunaan sarana produksi meningkat. Sebaliknya harga tomat rendah cenderang petani untuk menguranggi luas lahan produksi, intensitas pemilihan bibit dan penggunaan sarana produksi akan rendah.

Melihat keadaan ini maka dirasa perlu diadakan penelitian lebih lanjut tentang analisis biaya dan penerimaan usahatani tomat di Desa Wakuli Kecamatan Kapontori Kabupaten Buton.

Berdasarkan dikemukakan pada diidentifikasikan permasalahan:

1. Berapa biaya yang dikeluarkan petani pada usahatani tomat di Desa Wakuli Kecamatan Kapontori Kabupaten Buton.

2. Berapa Penerimaan yangdiperoleh dari usahatani tomat di Desa Wakuli Kecamatan Kapontori Kabupaten Buton.

Tujuan penelitian adalah sebagai berikut:

1. Untuk mengetahui besarya dikeluarkan pada usahatani tomat di Desa Wakuli Kecamatan Kapontori Kabupaten Buton

2. Untuk mengetahui apakah besamya penerimaan yang diperoleh dari usahatani tomat di Desa Wakuli Kecamatan Kapontori Kabupaten Buton.

Penelitian ini diharapkan dapat bermanfaat sebagai:

1. Bahan informasi bagi petani tomat dalam memasarkan hasil produksi agar pendapatannya dapat meningkat.

2. Bahan informasi bagi badan/instansi yang berhubungan dengan pengambilan kebijakan produksi tomat.

3. Bahan informasi bagi peneliti lainnya yang sejenis, agar dapat dijadikan sebagai pembanding untuk penelitian selanjutnya

\section{METODE PENELITIAN}

Penelitian ini dilaksanakan di Desa Wakuli Kecamatan Kapontori Kabupaten Buton, mulai bulan Juni sampai dengan Juli 2015.

Populasi dari penelitian ini adalah petani yang melakukan usahatani tomat yang ada di Desa Wakuli Kecamatan Kapontori Kabupaten Buton adalah 30 orang, sehingga dilakukan metode sensus dengan mengambil seluruh responden yang berjumlah 30 orang. Menurut Sugiyono (1998), jika populasi diatas 100 orang maka dapat dilakukan sampel 20\%-30\%, namum jika populasi dibawah 100 orang maka dilakukan sampel seluruhnya.

Teknik pengambilan data yang akan dilakukan adalah sebagai berikut:

1. Menggunakan kuesioner atau angket. Masyarakat yang meniadi obiek penelitian 
diperoleh datanya dengan menggunakan kuesioner yang telah disusun sedemikian rupasehingga data yang dibutuhkan dapat diperoleh secara maksimal.

2. Metode wawancara. Metode ini digunakan untuk memperoleh data yang selain dari kuesioner dan dokumen.

3. Observasi. Observasi atau pengamatan langsung dilakukan untuk mencocokkan data dan Informasi yang didapatkan dari hasil wawancara dengan keadaan sebenamya di lapangan.

Variabel yang diamati dalam penelitian ini adalah:

1. Identitas responden yangmeliputi umur, tingkat pendidikan, jumlah tanggungan keluarga,pengalaman berusahatani tomat.

2. Keadaan usahatani meliputi luas lahan, penerimaan, biaya, produksi dan harga jualtomat.

Teknik analisa data dalam penelitian ini dianalisis deskriptif kualitatif dan kuanlitatif. Untuk membuktikan pendapatan usahatani tomat yang diperoleh dan perhitungan, untuk mengetahui besamya biaya yang dikeluarkan oleh petani digunakan formulasi: $\mathbf{T C}=\mathbf{T E C}+$ TVC (Ken Suratiyah, 2006).

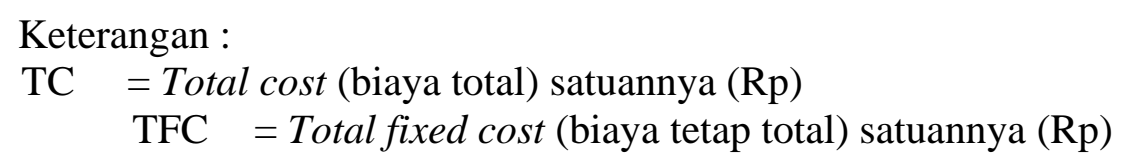

$\mathrm{TVC}=$ Total variabei cost (biaya variable) total satuannya $(\mathrm{Rp})$

Sedangkan untuk menghitung besamya penerirnaan yang diperoleh petani tomat adalah dengan formulasi $\mathbf{T R}=\mathbf{P} \times \mathbf{Q}$ ( Ken Suratiyah, 2006).

\footnotetext{
Keterangan :

NI = Net Income (pendapatan bersih) satuannya (Rp)

$\mathrm{TR}=$ Total Revenu (penerirnaan total) satuannya (Rp)

$\mathrm{TC}=$ Total cost (biaya total) satuannya (Rp)

$\mathrm{P} \quad=$ Price (harga jual produksi) satuannya $(\mathrm{Rp} / \mathrm{kg})$

$\mathrm{Q} \quad=$ Kuantitas (jumlah produksi) satuannya $(\mathrm{Rp} / \mathrm{kg})$
}

Definisi operasional variabel dalam penelitian ini bertuiuan untuk mendefinisi variabel agar tidak bias yaitu sebagai berikut:

a. Petani adalah orang yang mengusahakan tanaman tomat.

b. Produksi adalah jumlah atau banyaknya tomat yang dihasilkan oleh petani (Kw. atau $\mathrm{Kg}$ )

c. Tenaga kerja adalah jumlah curahan tenaga kerja pada usahatani tomat (Rp/HOK).

d. Harga jual adalah harga tomat yang berlaku ditingkat petani ( $\mathrm{Rp} / \mathrm{kg}$ atau $\mathrm{Rp} / \mathrm{Kw})$

e. Biaya usahatani tomat adalah keseluruhan biaya yang dikeluarkan oleh petani tomat (Rp).

f. Penerirnaan usahatani tomat adalah produksi tomat dikalidengan harga jual ditingkat petani dalam satuan $(\mathrm{Rp})$.

g. Pendapatan adalah jumlah penerirnaan dikurangi biaya yang dikeluarkan petani dalam satu kali panen (Rp).

\section{HASIL DAN PEMBAHASAN}

\section{Analisis Biaya dan Penerimaan Usahatani Tomat}

Masalah harga dalam kegiatan usahatani merupakan faktor perangsang dalam produksi. Jika harga tomat naik akan memberikan kontribusi pendapatan yang memadai bagi petani, sehingga para petani akan terdorong untuk meningkatkan produksinya. Sebaliknya jika harga 
tomat turun motivasi petani untuk meningkatkan produksinya kurang disebabkan karena harga dari usahataninya tidak memberikan kontribusi pendapatan yang memadaibagi petani. Oleh karena itu masalah harga ini untuk menjaga kestabilannya sangat penting sebagai salah satu alat kebijaksanaan untuk menggairankan para petani dalam berproduksi. Ketidakstabilan harga atau terjadinya fluktuasi harga akan mempengaruhi tingkah laku petani dalam merencanakan produksinya.

Keadaan fluktuasi harga sering dialami oleh para petani sehingga pada saat-saat tertentu dapat kita temukan harga hasil usahatani kadang-kadang naik dan kadang-kadang turun. Keadaan fluktuasi harga ini dapat pula terjadipada usahatani tomat di Desa Wakuli. Fluktuasi harga pada prinsipnya mempunyai pengaruh pada penggunaan faktor produksi yang dimaksud disini menyangkut luas lahan, penggunaan pupuk dan produksi.

Untuk rnenganalisis lebih jauh biaya dan penerimaan usahtani tomat di Wakuli dapat diuraikan sebagai berikut.

\section{Analisis Biaya Usahatani Tomat}

Biaya yang dikeluarkan petani adalah terdiri dari biayavariabei dan biaya tetap. Biaya variabel disebut juga biaya langsung yaitu biaya yang berhubungan dengan jumlah yang akan diproduksi atau biaya yang berhubungan dengan jumlah yang akan diproduksi atau biaya yang dikeluarkan apabila dilakukan proses produksi. Biaya variabel ini terdiri dari Biaya benih, pupuk, pestisida dan biaya tenaga kerja. Sedangkan biaya tetap terdiri dari penyusutan alat dan pajak tanah. Untuk lebih jelaskan tentang biaya dapat dilihat pada tabel 2.

Tabel 2. Rata-rata biaya usahatani tomat di Desa Wakuli, 2013.

\begin{tabular}{llr}
\hline No & Uraian & Jumlah (Rp) \\
\hline 1. & Biaya Variabel (VC) & 338.767 \\
& a. Benih & 1.2227 .333 \\
& b. Pupuk & 647.917 \\
& c. Pestisida & 2.716 .667 \\
& d. Tenaga Kerja & \\
2 & Biaya Tetap & 750.000 \\
& a. Penyusutan Alat & 35.000 \\
& b. Pajak Tanah & 5.715 .638 \\
\hline
\end{tabular}

Berdasarkan hasil analisis dan perhitungan biaya yang dikeluarkan dalam usahatani tomat di desa Wakuli adalah rata-rata biaya Rp. 5.715.983,-(lampiran 3). Hal ini menunjukan bahwa biaya-biaya yang dikeluarkan sangat menentukan dalam produksi usahatani dan pendapatan tomat dilokasi penelitian baik berapa biaya variabel (benih, pupuk, pestisida dan tenaga kerja)dan biaya tetap seperti pajak tanah dan penyusutan peralatan.

\section{Analisis Penerimanaan Usahatani Tomat}

Penerimaan dalam usahatani tomat sangat dipengaruhi oleh jumlah produksi dan harga yang didapatkan oleh petani. Sering kali produksi yang dihasilkan cukup tinggi tapi harga yang diterima rendah. petani mengalami kerugian dalam usahataninya. Hasil tabel diatas menunjukan rata-rata produksi pcrhektar adalah $\mathrm{Rp} .2 .861,-/ \mathrm{Kg}$ serta rata-rata harga perkilogram Rp.5.000, dengan penerimaan rata-rata Rp. 14.303.667,- (lampiran 3). Dengan rata-rata penerimaan ini menunjukkan bahwa daerah penelitian ini masih dikategorikan sedang karena masiii ada iahan-iahan pertanian yang belum dimanfaatkan secara optimal yang 
nantinya akan memberikan pendapatan yang optimal seperti digambarkan pada Tabel 3 sebagai berikut:

Tabel 3. Rata-rata penerimaan usahatani Tomat di Desa wakuli, 2013.

\begin{tabular}{llr}
\hline \multicolumn{1}{c}{ No. } & \multicolumn{1}{c}{ Uraian } \\
\hline 1. & Penerimaan & Jumlah $(\mathrm{Rp} / \mathrm{Kg})$ \\
& a. Produksi & $2.861 / \mathrm{Kg}$ \\
& b. Harga & $5.000 \mathrm{Rp} / \mathrm{Kg}$ \\
2 & Penerimaan (R) & Rp. 14.303 .667 \\
\hline
\end{tabular}

Rata-rata pendapatan yang diterima petani responden usahatani tomat di Desa Wakuli Kecamatan Kapontori adalah:

$$
\begin{aligned}
\mathrm{Ni} & =\mathrm{TR}-\mathrm{TC} \\
\mathrm{Ni} & =\text { Rp. } 14.303 .667-\mathrm{Rp} .5 .715 .683 \\
& =\text { Rp. } 8.587 .984
\end{aligned}
$$

Dari angka ini menunjukkan bahwa pendapatan bersih yang diterima petani responden di lokasi penelitian dirasakan cukup untuk memenuhi kebutuhan hidup minimum, hal ini pula diperkuat dengan pendapat Sejogyo dalam Muhude (1996), dikatakan bahwa untuk wilayah pedesaan standart kebutuhan minimumnya jika dinilai dengan rata-rata pendapatan sebesar Rp.2.500.000,- Di lain pihak petugas penyuluh lapangan mengatakan bahwa pada daerah lokasi penelitian ini rata-rata petani menanam tanaman hortikultura yang merupakan tanaman tumpang sari, karena mayoritas petani padi sawah.

\section{a. Kesimpulan}

\section{KESIMPULAN DAN SARAN}

Berdasarkan uraian hasil penelitian, maka dapat dismipulkaii sebagai berikut:

1. Biaya yang dikeluarkan petani dalam melakukan kegiatanusahatani tomat dengan luas lahan rata-rata 1 ha dengan rata-rata biaya Rp. 5.715.983,-

2. Demikian pula rata-rata penerirnaan Rp. 14.303.667, dengan luas lahan garapan antara 0.25-2 ha dengan pendapatan rata-rata petani responden adalah $\mathrm{Rp}$. 8.587.983,-

\section{b. Saran}

Dari kesimpulan hasil penelitian tersebut, maka dapat disarankan adalah sebagai berikut:

1. Petani tomat di Desa Wakuli perlu memberdayakan lembaga pemasaran yang berbentuk Koperasi Unit Desa, sehingga menjadi lembaga pemasaran yang dapat menampung hasil usahatani tomat serta dapat berfungsi untuk dapat mnciptakan kestabilan harga.

2. Pemerintah daerah terutama ditingkat kabupaten perlu menetapkan peraturan-peraturan yang berhubungan dengan sistem pemasaran tomat terutama penetapan harga dasar.

\section{DAFTAR PUSTAKA}

Anwas Adiwiiaga, 1982. Ilmu Usahatani. Alumni. Bandung.

Badan Pusat Statistik Kabupaten Buton, 2010-2012, Buton Dalam Angka 2010-2012. Kantor Badan Pusat Statsitik Kabupten Buton, Pasarwajo.

Dinas Pertanian Kabupaten Buton, 2010-2012. Laporan Tahunan Dinas Pertanian Kabupaten Buton. Pasarwajo.

G. Kartasapoetra dkk, 1992. Marketing Produk Pertanian dan Industri yang Diterapkan di Indonesia. PT. BinaAksara. Jakarta. 
Ken Suratiyah, 2006. Ilmu Usahatani. PT. Remaja. Jakarta.

Irawan, 2003. Azas-Azas Manajemen Produksi. Bumi Aksara. Jakarta.

Irawan et a!, 2006. Menggerakan dan Membangun Pertanian. CV. Yasaguna, Jakarta.

Richard, H Letwich, 1984. MikroEkonomi. Diterjemahkan oleh St. Dianjung. PT. Bina Aksara. Jakarta.

Purwanti dan Asga, 1990. Agrobisnis Tanaman Hias. Peneribit Swadaya. Jakarta.

Saefuddin A.M., 1982.Pengkajian Pemasaran Komoditi, Diktat Pascasarjana Institut Pertanian Bogor. Bandung.

Sundstrom, 1982. Manajemen Produk Modern. Fakultas Ekonomi Universitas Indonesia. Jakarta.

Soekartawi, 1990. Teori Ekonomi Produksi dengan Pokok Bahasan, Analisis Fungsi CobbDouglas. Rajawali Press. Jakarta.

, 2001. Agribisnis Teoridan Aplikasinya Cetakan ke-6. PT. Raja Grafindo Persada. Jakarta.

Wijayan L, 2000. Dasar-Dasar Manajemen Umum. Pustaka Dian. Jakarta.

Winardi, 1980. Azas-Azas Marketing. Penerbit Alumni.Bandung. 